\section{Corneal guttata: a comparative clinical and specular micrographic study}

\begin{abstract}
Background The relationship between corneal guttata and Fuchs' endothelial dystrophy is unclear, with the result that the clinical differentiation of the two conditions is often made on the basis of the presence or absence of symptoms.

Methods In this study the authors compare the clinical and specular micrographic findings, as recorded from 20 patients noted to have biomicroscopic clinical findings consistent with corneal guttata or early Fuchs' endothelial dystrophy.

Results Results confirm the increased prevalence of corneal findings in elderly women. The topographical distribution of guttata, across the posterior corneal surface, as observed clinically was confirmed specular micrographically $\left(r_{S}=0.55, p=0.01\right)$. Increased numbers of guttata correlated with a statistically significant reduction in the endothelial cell counts recorded from the midperipheral cornea $\left(r_{S}=0.49, p=0.02\right)$. The relationship between the presence of guttata and a reduction in cellular hexagonality or an increase in polymegethism failed to reach a statistically significant level. Pigment deposits adherent to the posterior endothelial surface were also noted in all but one of the eyes examined.

Conclusions The authors advocate the use of a grading scale, developed from specular micrographs taken during the course of the study, to assist in the clinical classification of corneal guttata and pre-clinical Fuchs' dystrophy. The authors also recommend specular microscopy as a tool capable of differentiating corneal guttata from pigment deposits in even the most severely affected cases.
\end{abstract}

Key words Corneal guttata, Fuchs' dystrophy, Specular microscopy

The term corneal guttata, first coined by Vogt in the $1930{ }^{1},{ }^{1}$ describes focal excrescences of collagenous basement membrane material which have accumulated on Descemet's membrane, across the central cornea. The excrescences are similar in appearance to the Hassall Henle bodies that can be found in the peripheral cornea and appear with increasing frequency with increased age. ${ }^{2}$ The frequency and severity of guttata which occur either randomly or in confluent form increase with age. $^{3}$ They are found in $10-80 \%$ of those over 40 years of age. ${ }^{4}$ Apparent discrepancies in reported prevalence figures may result from variations in classification criteria, many elderly patients with clinically definable corneal guttata having been classed as normal for age. Occasionally primary central corneal guttata progress to Fuchs' endothelial dystrophy, a bilateral and often symmetrical degenerative disease of the cornea in which endothelial decompensation and corneal hydration occur. ${ }^{5,6}$ Fuchs' dystrophy, first described in 1902, ${ }^{7}$ exhibits an autosomal dominant inheritance pattern and has a high degree of penetrance and variable expression. ${ }^{6}$ It is generally more pronounced in women; men of similar age are up to 3 times less likely to develop Fuchs' dystrophy. ${ }^{2}$ The incidence of both corneal guttata and Fuchs' dystrophy is reportedly much lower in Japan. ${ }^{8}$

Although Fuchs' dystrophy accounts for between $13 \%$ and $30 \%$ of corneal transplantations in the United Kingdom and North America, the exact prevalence and incidence of the condition are unknown. ${ }^{6,9,10}$ At present there are no predictors as to which corneal guttata patients will proceed to Fuchs' corneal endothelial dystrophy. Corneal guttata and Fuchs' dystrophy have been shown to occur in association with a number of other conditions. ${ }^{2,6}$ Of particular interest is a reported association between impaired aqueous outflow, glaucoma and the presence of corneal guttata. ${ }^{11}$ This finding is, however, controversial and disputed by other authors. ${ }^{12}$ Fuchs' dystrophy has also been shown to have an association with axial hypermetropia and angle closure glaucoma. ${ }^{13,14}$ Keratoconus, $^{15}$ ocular trauma ${ }^{16}$ and a long-standing history of intraocular inflammation ${ }^{17}$ have also been associated with

\author{
A.J. Jackson \\ D.B. Archer \\ Department of \\ Ophthalmology \\ Faculty of Medicine \\ The Queen's University of \\ Belfast \\ Belfast \\ Northern Ireland, UK
}

\section{A.J. Jackson \\ F.O. Robinson \\ D.G. Frazer \\ D.B. Archer \\ Department of \\ Ophthalmology \\ Royal Victoria Hospital \\ Belfast \\ Northern Ireland, UK}

\section{Dr A. J. Jackson \\ Department of \\ Ophthalmology \\ Royal Victoria Hospital \\ Grosvenor Road \\ Belfast BT12 6BA \\ Northern Ireland, UK \\ Tel: (01232) 240503 \\ ext. $4128 / 4129$}

Received: 19 January 1999 Accepted in revised form: 12 July 1999 
the presence of corneal guttata. Transient guttata-like features (pseudoguttata) have also been noted secondary to trauma or intraocular inflammation and these are thought to result from endothelial oedema or pigmentation. ${ }^{18}$ An association between cardiovascular disease, corneal guttata and Fuchs' dystrophy has also been reported. ${ }^{19}$

This study reports on and compares the clinical and specular micrographic findings from eyes noted to have corneal guttata.

\section{Materials and methods}

Twenty consecutive Caucasian patients identified in general ophthalmology clinics as having corneal guttata or endothelial pigmentation were referred to the hospital's regional specular microscopy service for examination. Eyes with a history of intraocular surgery, ocular trauma, keratitis or anterior segment

inflammation were excluded from the study. Thirty-one eyes, confirmed as having corneal guttata or endothelial pigmentation in the absence of other significant findings, were included in this study. All patients were examined clinically by one of two examiners (F.O.R., A.J.J.). A detailed ocular and general history was taken and information on the severity and extent of patient's symptoms was also recorded. The distribution of corneal guttata and pigment deposits centrally and in four midperipheral corneal sites (medially, laterally, superiorly and inferiorly) were documented. A grading system was established in which guttata were graded on a $0-5$ scale and pigmentary changes on a scale of $0-4$ (Table 1$)$. A general anterior segment examination, which included applanation tonometry and gonioscopy, was performed. Iris patterns were graded according to colour and texture. Slit-lamp biomicroscopic findings together with clinical and general historical data were obtained from 16 phakic age-matched controls currently under investigation for lens opacities ( 5 men, 11 women; mean age 71.5 years). Each of these patients was noted to be free of guttata on clinical examination.

Table 1. Clinical grading scales for corneal guttata and endothelial pigment deposits

\begin{tabular}{|c|c|c|}
\hline Grade & Guttata & Pigmentary change \\
\hline 0 & No guttata seen & No pigment seen \\
\hline 1 & $\begin{array}{l}\text { A few isolated scattered } \\
\text { guttata }\end{array}$ & $\begin{array}{l}\text { A few isolated pigmented } \\
\text { deposits }\end{array}$ \\
\hline 2 & $\begin{array}{l}\text { Widespread scattered } \\
\text { guttata becoming small } \\
\text { confluent patches }\end{array}$ & $\begin{array}{l}\text { A fine dusting of isolated } \\
\text { pigment deposits }\end{array}$ \\
\hline 3 & $\begin{array}{l}\text { Larger confluent patches } \\
\text { of guttata }\end{array}$ & $\begin{array}{l}\text { A moderate dusting of } \\
\text { pigment deposits } \\
\text { becoming confluent }\end{array}$ \\
\hline 4 & $\begin{array}{l}\text { Diffuse carpet of large } \\
\text { confluent guttata }\end{array}$ & $\begin{array}{l}\text { Very prominent } \\
\text { pigmentary confluent } \\
\text { deposits }\end{array}$ \\
\hline 5 & $\begin{array}{l}\text { Widespread diffuse } \\
\text { carpet of confluent } \\
\text { guttata with evidence of } \\
\text { epithelial oedema }\end{array}$ & \\
\hline
\end{tabular}

Specular microscopy was performed by a single examiner (A.J.J.) using the Keeler Konan Pocklington specular microscope. Examination procedures were as outlined in the standard text on the subject, although therapeutic lenses were not used during the course of the examination. ${ }^{20}$ An average of $12 \pm 3$ (SD) micrographs were taken per eye. Micrographs illustrating the appearance of the corneal endothelium, centrally and in all four mid-peripheral quadrants, were selected for semi-automated quantitative analysis using the Kontron Mop II videoplan. Between 100 and 200 cells were assessed in each eye under investigation. The mean number of cells assessed per quadrant was $47 \pm 23$ (SD). Measurements of cell area, diameter and perimeter were recorded and results were expressed as means and variances. Polymegethism (variation in cell size) and pleomorphism (variation in cell shape) together with cellular form factors and skewness indices were assessed. Pachymetry was performed centrally and in four midperipheral regions using the specular microscope's pachometer. Specular microscopy was not performed on the control sample. Predicted cell counts, taking account of age, were calculated from published normative data. ${ }^{21-23}$ Published age-matched normative data were used to calculate predicted pleomorphism and polymegethism. $^{21,24}$ Patient results were expressed as deviation from predicted values. In order to obtain a valid statistical analysis one eye was selected at random from bilaterally affected individuals. The one-tailed $t$-test was used to assess whether mean deviations differed significantly from zero. Association between variables was assessed using Spearman's non-parametric rank correlation coefficient.

\section{Results}

The mean age of the 20 patients, 16 of whom were female, was $73.8 \pm 8.9$ (SD) years (male 74.5 years/ female 73.6 years). Thirteen patients presented with a primary complaint of reduced vision in at least one eye. Three patients described glare as a primary complaint while a further 2 described pain as a significant ocular finding. Only 2 patients were symptom-free. No patient gave a history of glaucoma or keratoconus. Ten eyes were excluded, there having been evidence of previous trauma $(n=2)$ or surgery (lens extraction with intraocular lens implantation $(n=4)$, penetrating keratoplasty $(n=1)$, triple procedure including lens extraction, intraocular lens implantation and penetrating keratoplasty $(n=3))$. Three patients had a history of cardiovascular disease and 6 patients offered a history of asthma. One patient had migraine, 1 arthritis and 2 diabetes. The general medical profile of the control population was similar (cardiovascular disease 5 /arthritis 1 /respiratory disorders 2). Only 1 patient gave a positive family history of Fuchs' endothelial dystrophy. Visual acuities ranged from $6 / 6$ to hand movements, $61 \%$ of eyes having a corrected acuity of $6 / 18$ or better. The visual acuities recorded from the 
control population were broadly similar, $56 \%$ having a best corrected acuity of $6 / 18$ or better (range $6 / 5$ to hand movements).

On slit-lamp biomicroscopic examination a HudsonStahli line was observed in all but one eye $(n=30)$. In contrast only 6 of the control patients showed any evidence of a Hudson-Stahli line. Endothelial pigment was present in the majority of eyes $(n=25)$. In one case the degree of endothelial pigmentation could not be assessed as the view was obscured by bullous corneal epithelial changes. Central guttata ranged from grade 1 to grade 5 , the majority of cases having been graded as 4 . Of the 11 patients in whom both eyes were examined, 8 patients had symmetrical grading of central guttata. In the remaining 3 , corneal guttata as recorded in the right and left eyes differed by a single grade. Peripheral guttata in the horizontal meridian ranged from grades 0 to 4 , medial and lateral changes being symmetrical in all cases. Superior and inferior changes, recorded in 24 eyes, ranged from grade 0 to 3 . In 20 eyes, symmetrical superior and inferior changes were noted whereas in 4 eyes guttata were more pronounced in the inferior site. No cases showed more advanced guttata superiorly. Pigment deposits, adhering to the endothelium, were noted in 25 of the 31 eyes examined. Indications were that there was no obvious correlation between the distribution and density of pigment deposits and the severity of corneal guttata as seen on biomicroscopy $\left(r_{\mathrm{S}}=0.29, p=0.21\right)$. In one eye exhibiting grade 1 guttata changes, grade 4 pigmentary changes were noted in the fellow eye.

The mean endothelial cell densities (sample mean $1868 \pm 797(\mathrm{SD})$ cells $/ \mathrm{mm}^{2}$ ) recorded from patients with corneal guttata were significantly reduced $(p<0.05)$ compared with predicted values determined from the normative data of Yee et al. ${ }^{21}{ }^{21}$ Bourne and Kaufman ${ }^{22}$ and Hoffer and Kraff. ${ }^{23}$ The mean reductions determined from these three normative samples were 730 cells $/ \mathrm{m}^{2}$ (95\% CI, 340-1100), 550 cells $/ \mathrm{mm}^{2}$ (95\% CI, 160-940) and 570 cells $/ \mathrm{mm}^{2}$ (95\% CI, 150-980), respectively. There were also statistically significant inverse correlations between the number of corneal guttata present and the endothelial cell counts, as expressed in terms of the deviation from the predictive normative data derived from the three studies (Yee $=r_{\mathrm{S}}=-0.49, p=0.03$; Bourne $=r_{\mathrm{S}}=-0.48, p=0.03$; Hoffer $=r_{\mathrm{S}}=-0.47, p=0.03$ ).

The proportion of cells contributing to the endothelial mosaic, which were hexagonal, varied from $48 \%$ to $84 \%$ (mean hexagonality $64 \% \pm 11$ SD). The extent of pleomorphism noted in the guttata study group did not differ significantly in comparison with the predicted values determined from the normative data of Yee et al. ${ }^{21}$ and Matsuda et al. ${ }^{24}$ The index of polymegethism, recorded in the eyes screened, varied from 0.14 to 0.41 (mean correlation $0.27 \pm 0.05 \mathrm{SD}$ ). The variations in polymegethism recorded were, surprisingly, marginally less than the predicted values determined from the normative data $(p<0.05) .{ }^{21,24}$ The mean (cov) reductions determined from the Yee et al. ${ }^{21}$ and Matsuda et al. ${ }^{24}$ normative samples were 0.03 (95\% CI, 0.01-0.06) and 0.04 (95\% CI, 0.01-0.06) respectively.

The correlation between clinical and specular micrographic gradings was good both centrally $\left(r_{\mathrm{S}}=0.55\right.$, $p=0.01)$ and in the mid-peripheral zones $\left(r_{\mathrm{S}}=0.77\right.$, $p=0.01$ ). The severity of central guttata noted on specular microscopy showed only a moderate inverse relationship with a generalised mid-peripheral reduction in endothelial cell count $\left(r_{\mathrm{S}}=-0.49, p=0.03\right)$. The inverse relationship became much more significant when a correlation was made between mid-peripheral cell counts and mid-peripheral guttata gradings (Fig. 1) $\left(r_{\mathrm{S}}=-0.67, p=0.001\right)$, Several exceptions were noted where individuals with cell count means of 3000 cells $/ \mathrm{mm}^{2}$ were found to have central guttata of grade 4 or above. Specular micrographic findings confirm that guttata assumed a characteristic geographical distribution in which the central cornea was most severely affected. Grading the guttata according to the extent to which they obscured endothelial cells and achieved confluence further confirmed clinical findings (Fig. 2). The distribution and density of the pigment deposits failed to correlate with the severity of guttata as recorded on specular micoscopy (central cornea $r_{\mathrm{S}}=0.047, p=0.86$; mid-peripheral cornea $r_{\mathrm{S}}=-0.068$, $p=0.78$ ) or with a reduction in the overall endothelial cell count (mid-peripheral cornea $r_{\mathrm{S}}=-0.24, p=0.32$ ). The pleomorphic indices, expressed in terms of the percentage of hexagonal cells contributing to the mosaic, show a positive correlation with endothelial cell count $\left(r_{\mathrm{S}}=0.59, p=0.09\right)$. Predictably there was an inverse relationship between hexagonality and polymegethism and the correlation was significant $\left(r_{\mathrm{S}}=-0.58, p=0.01\right)$. In those cases where guttata had become confluent, thus obscuring endothelial cell detail, the clinical differentiation of guttata, pigment and diffuse posterior stromal scarring became difficult. Specular microscopy proved useful in differentiating between pigment deposits and guttata even in those cases where guttata were widespread (Fig. 3). Five cases were noted to have such widespread guttata that central corneal endothelial cell counts could not be assessed with any degree of

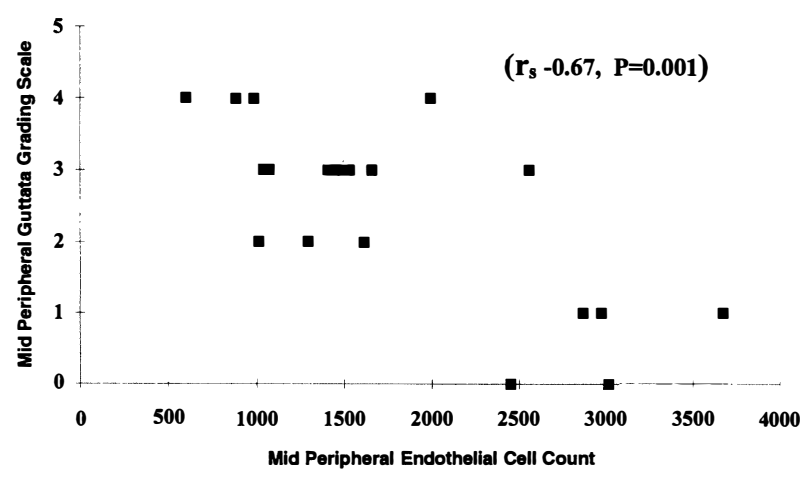

Fig. 1. Relationship between mid-peripheral endothelial cell counts as determined by specular microscopy, and the relative density of central corneal guttata determined clinically ( $n=20$ eyes). 


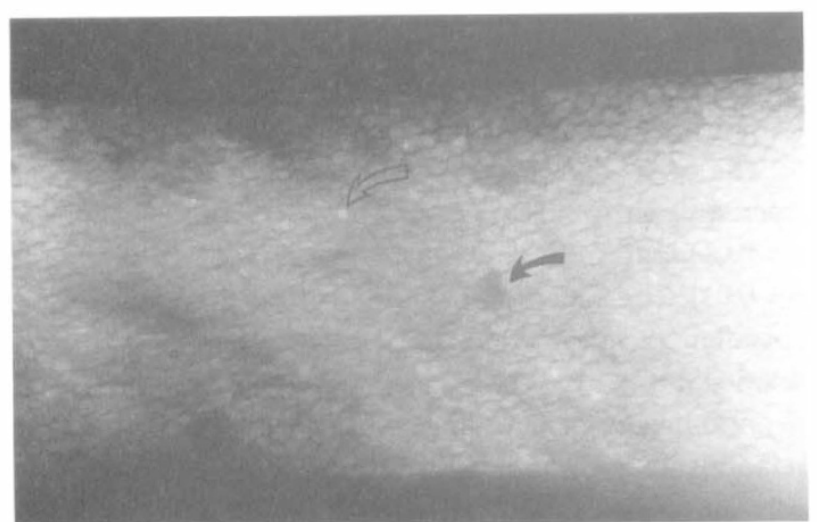

(a)

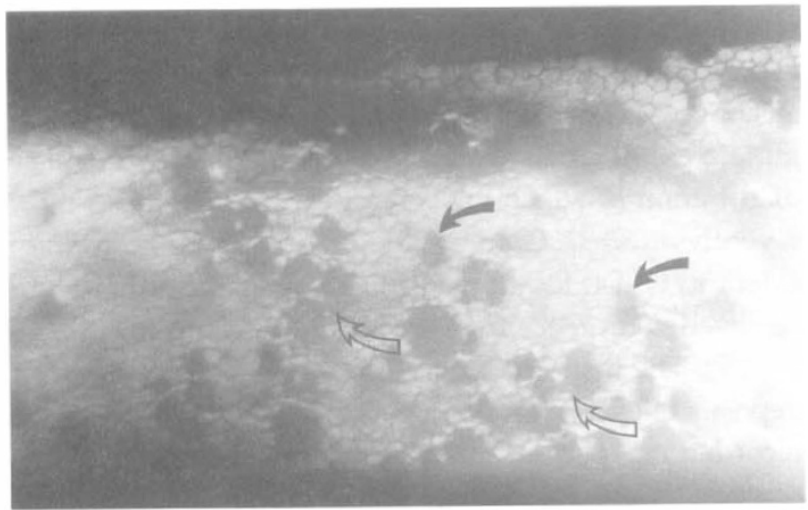

(c)

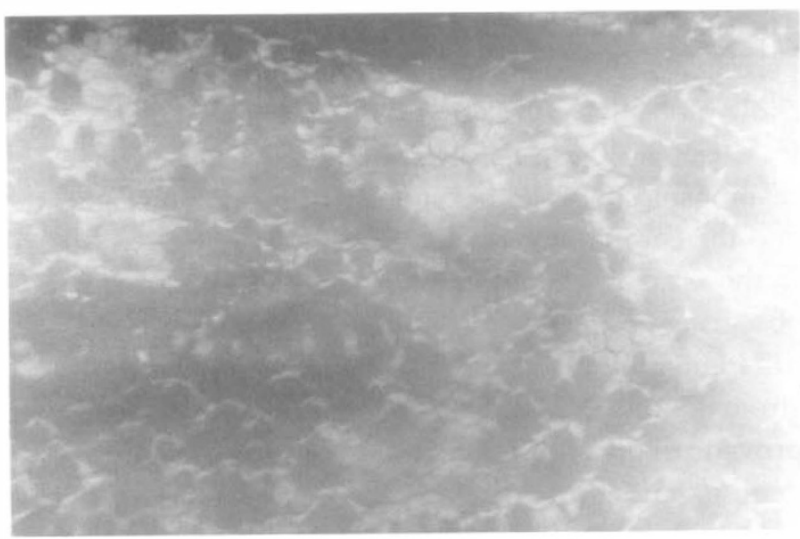

(e)

Fig. 2. (a)-(f). For legend see facing page.

reliability, hence the importance of recording midperipheral counts in multiple quadrants. Forty per cent of cases were noted to have mid-peripheral counts of in excess of 2000 cells $/ \mathrm{mm}^{2}$. In only $16 \%$ of cases were the cell counts less than 1000 cells $/ \mathrm{mm}^{2}$. In one-third of cases the central corneal thicknss measured in excess of $0.59 \mathrm{~mm}$ (mean $0.58 \pm 0.06$ (SD) $\mathrm{mm}$, range

$0.42-0.69 \mathrm{~mm}$ ). There were no signs of anatomical lid abnormalities in any of the cases examined. Fourteen of the eyes examined had blue iris coloration, 9 exhibited a mottled appearance, neither predominantly blue nor brown, and 7 had brown irides. There were no signs of pseudoexfoliation in any of the eyes examined.

Intraocular pressures were normal, gonioscopy revealed

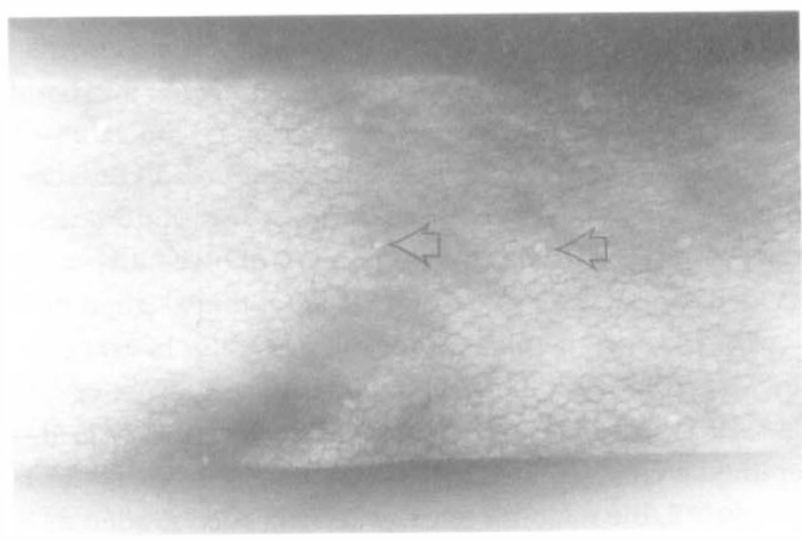

(b)

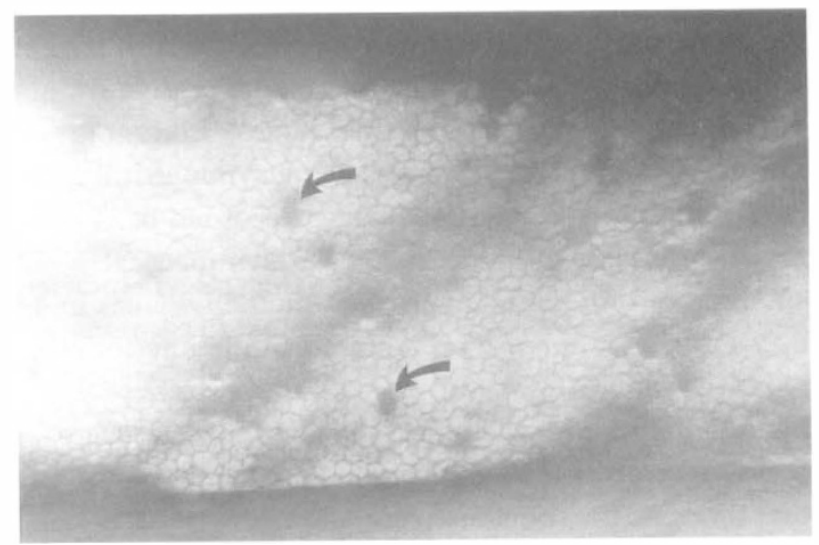

(d)

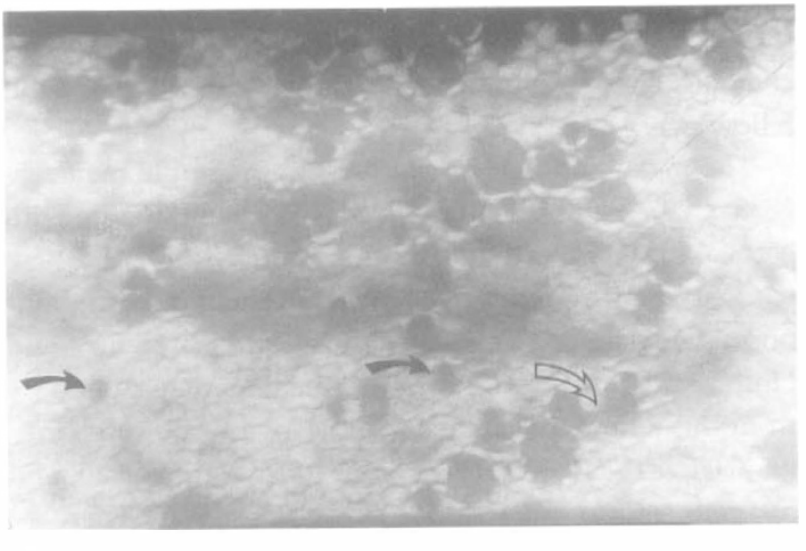

(f)

open angles and findings were symmetrical in all cases. The majority of eyes had at least early lens opacities $(n=22)$.

\section{Discussion}

In this study, 20 patients with central corneal guttata were examined clinically and by specular microscopy. The majority were elderly women, which is in keeping with the previous finding that Fuchs' endothelial dystrophy occurs 2.5 times more often in women than men. ${ }^{25}$ This finding is inconsistent with a proposed autosomal dominant inheritance. It is also unlikely to be attributable solely to increased female longevity and may indicate that guttata changes appear earlier in women. 


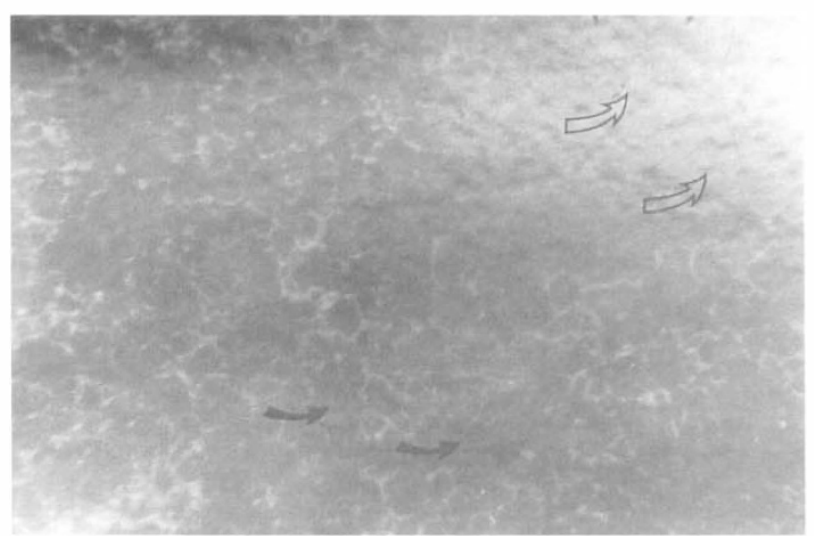

$(g)$

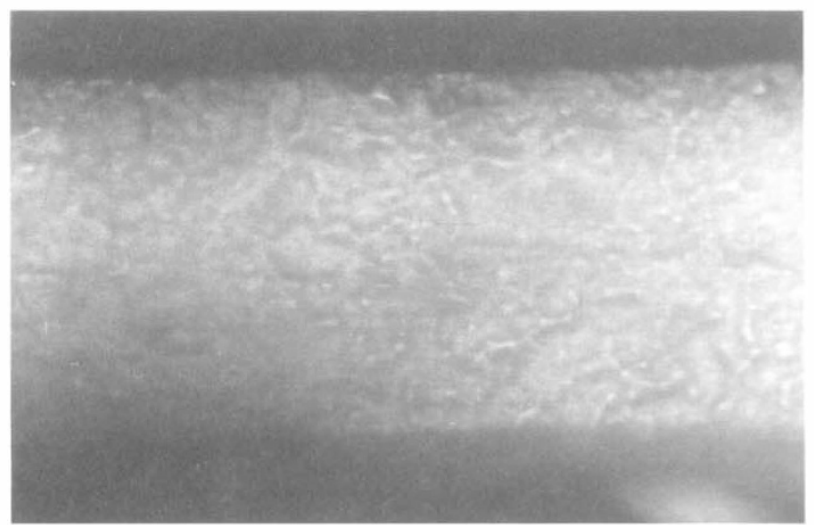

(i)

Fig. 2. (a) Grade I guttata, central cornea. Central cornea (KS): isolated central guttata (filled arrows) and grade I pigment deposits (open arrows). Cell density 1926 cells $/ \mathrm{mm}^{2}, \mathrm{COV}$ cell area 0.16. (b) Grade I guttata, mid-peripheral cornea. Inferior cornea (KS): guttata-free area with grade I pigment deposits (open arrows). Cell density 1869 cells $/ \mathrm{mm}^{2}, \mathrm{COV}$ cell area 0.16. (c) Grade II guttata, central cornea. Central cornea (LG): isolated central guttata (filled arrows) interspersed between confluent guttata (open arrows). Cell density $1919 \mathrm{cells} / \mathrm{mm}^{2}$, COV cell area 0.29. (d) Grade II guttata, mid-peripheral cornea. Inferior cornea (LG): isolated mid-peripheral guttata (filled arrows). Cell density 2114 cells/mm ${ }^{2}$, COV cell area 0.34. (e) Grade III guttata, central cornea. Central cornea (JD): confluent patches of central guttata. Cell density 1353 cells/mm ${ }^{2}$, COV cell area 0.31. (f) Grade III guttata, mid-peripheral cornea. Superior cornea (JD): combination of isolated (filled arrows) and confluent (open arrow) guttata in the mid-peripheral cornea. Cell density 1206 cells $/ \mathrm{mm}^{2}, \mathrm{COV}$ cell area 0.25. (g) Grade IV guttata, central cornea. Central cornea (EW): widespread confluent central guttata visible in both direct (filled arrows) and retro-illumination (open arrows). Endothelial cell coverage is obscured. (h) Grade IV guttata, mid-peripheral cornea. Lateral cornea (EW): confluent mid-peripheral corneal guttata. Cell density 1948 cells/mm ${ }^{2}$, COV cell area 0.33. (i) Grade V guttata, central cornea. Central cornea (MR): widespread central and mid-peripheral confluent guttata giving the corneal endothelial surface a characteristic beaten-metal appearance. Endothelial cell coverage is obscured. Central corneal thickness 0.57 mm. (j) Grade $V$ guttata, mid-peripheral cornea. Central corneal (MM): specular micrographic appearance of a decompensated cornea characterised by epithelial oedema and bullae (filled arrows). Central corneal thickness $0.79 \mathrm{~mm}$.

Ultrastructural evidence suggests that abnormalities in the posterior banded collagen layer of Descemet's membrane are evident early in life in both male and female patients affected by corneal guttata or Fuchs' dystrophy. ${ }^{26}$ Pedigree analysis has further shown that the penetrance or expressivity of guttata is unlikely to be higher in women. ${ }^{27}$ Lorenzetti et al. ${ }^{4}$ who have reported on one of the largest series of corneal guttata cases ( $n=1016)$, although finding a female to male ratio of only $1: 1$, noted that guttata found in older women were generally of a more clinically significant nature. Magovern et al. ${ }^{28}$ have reported similar equal sex ratios in the study of Fuchs' dystrophy in a large fourgeneration family of 64 individuals. Although the bulk of data on Fuchs' dystrophy and corneal guttata would appear to support an autosomal dominant mode of inheritance, ${ }^{2}$ only one patient in this study gave a positive family history of this disease, based on symptoms. Interestingly the same patient, although having excessive central corneal guttata, had a normal mid-peripheral cell count. The predisposition of females in the report from Krachmer et al. ${ }^{25}$ and this group to a certain extent provide contradictory evidence for an autosomal dominant mode of inheritance and may be attributed either to recruitment bias or to the possibility that Fuchs' dystrophy and corneal guttata represent a group of heterogeneous disorders caused by a combination of environmental and genetic factors. ${ }^{2,29}$

Having reviewed the main complaints, and looked at them in respect of the clinical findings, it was felt that in only 4 of the patients examined in this study were the symptoms of reduced vision, glare and pain due to corneal endothelial dysfunction, resulting in stromal or epithelial oedema. The majority of causes of reduced vision were attributable to lens opacities. In accordance with the clinical grading of Fuchs' dystrophy, ${ }^{6} 2$ patients 


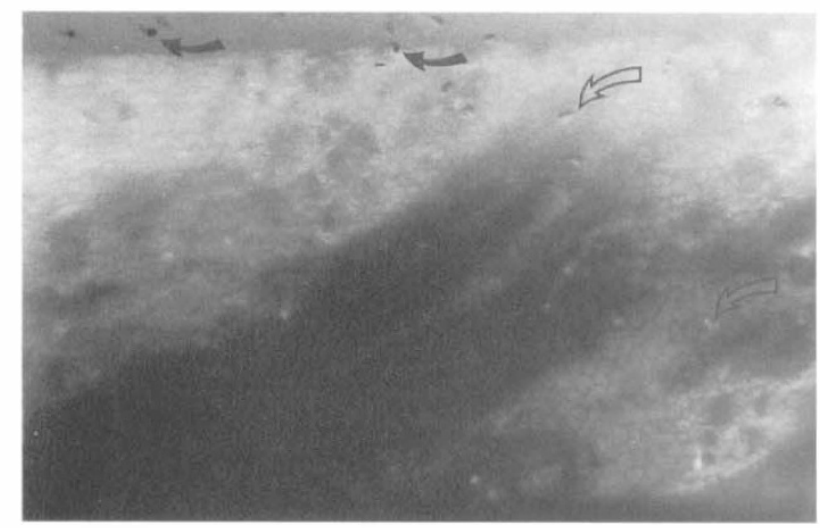

(a)

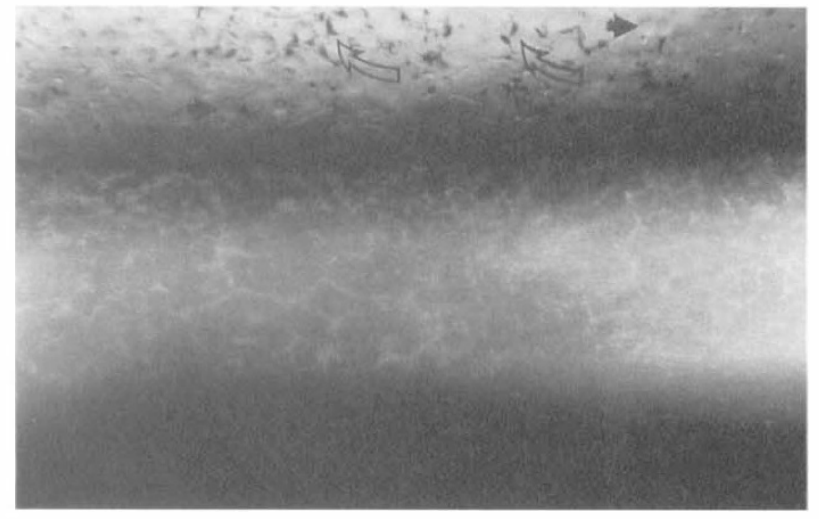

(b)

Fig. 3. (a) Grade III corneal endothelial pigment. Central pigment deposits (open arrows) on a grade I guttata cornea. Flecks are particularly prominent when viewed in retro-illumination (filled arrows). (b) Grade IV endothelial pigment. Cluster of grade IV central pigment deposits on a grade IV guttata cornea. Retro-illumination assists in the differentiation of pigment deposits (open arrows) from guttata (filled arrows).

had reached stage 2 (a painless decrease of vision and glare) and 2 patients stage 3 (bullae causing episodes of pain). The majority of our study patients were asymptomatic and could thus be classified as having primary central corneal guttata or alternatively stage 1 or pre-clinical Fuchs' corneal endothelial dystrophy.

Clinically it was not possible to differentiate the two conditions other than on the basis of grading the extent to which guttata covered the endothelial surface and subsequently affected endothelial function. ${ }^{30}$ None of the patients gave a history of glaucoma or keratoconus. This is in contrast to the previous studies which have claimed an association between Fuchs' dystrophy and these conditions. ${ }^{11,13,15}$ Three of our patients had a history of cardiovascular disease. This was not significantly higher than the age- and sex-matched control group, with 2 affected out of 17 cases selected as controls from a group of patients with uncomplicated senile cataract. This finding contrasts with previous studies, which reported a higher prevalence of cardiovascular disease in Fuchs' dystrophy. ${ }^{19}$ In this study we were dealing specifically with central corneal guttata and pre-clinical Fuchs' dystrophy and not full-blown Fuchs' dystrophy. Six of our patients gave a history of asthma, compared with 1 of our control group. No association between asthma and guttata has previously been made.

In previous studies guttata have been described as first appearing centrally and thereafter appearing peripherally within the confines of the palpebral aperture. ${ }^{4,6}$ Our study verified this, all eyes having exhibited the highest concentration of guttata centrally. In all cases the ratio of guttata appearing medially and laterally within the palpebral aperture in any one eye was equal. Superior and inferior gradings were essentially equal although there was a tendency for more guttata to appear inferiorly. In these cases the relative paucity of guttata in the superior cornea may reflect differing rates of exposure to environmental lighting and ultraviolet radiation, the superior cornea having been partially protected by the upper lid.
Increased numbers of guttata were associated with a reduced endothelial cell count in the majority of cases. In 4 cases, noted to have grade 3-4 central guttata, the midperipheral endothelial cell counts were markedly higher than expected ( $>2500$ cells $/ \mathrm{mm}^{2}$ ). We could find no reason to account for this. The appearance of the corneal endothelium, when viewed in specular mode, differed according to the extent to which corneal guttata covered the endothelial surface (Fig. 2a-i). These confirm many of the features previously noted by Laing et al..$^{31}$ and Olsen. ${ }^{32}$ Twenty-seven eyes had a Hudson-Stahli line. With respect to iris colour, all cases with a mottled appearance showed extensive corneal guttata. The significance of these findings is unknown although the association is more likely to represent co-inheritance of the traits than a causative connection.

The authors are grateful to Dr C. Patterson for statistical assistance throughout the course of the study and to Mrs M. Loughran for secretarial support.

\section{References}

1. Vogt A, Wagner H, Rickner H, Meyer G. Inheritance of corneal guttata. Arch Julius Klaus-Stift, Vererbungsforsch 1939;14:475-597.

2. Wilson SE, Bourne WM. Fuchs' dystrophy. Cornea 1988;7:2-18.

3. Arffa RC. Disorders of the endothelium. In: Grayson's diseases of the cornea. 3rd ed. St Louis: Mosby Year Book, 1991.

4. Lorenzetti DWC, Uotila MH, Parikh RNN, Kaufman HE. Central cornea guttata: incidence in the general population. Am J Ophthalmol 1967;64:1155-8.

5. Rosenblum P, Stark WJ, Maumenee IH, Hirst LW, Maumenee E. Hereditary Fuchs' dystrophy. Am J Ophthalmol 1980;90:455-62.

6. Adamis AP, Filatov V, Tripathi BJ, Tripathi RC. Fuchs' endothelial dystrophy of the cornea. Surv Ophthalmol 1993;38:149-68.

7. Fuchs E. Dystrophia epithelialis cornea. Graefes Arch Klin Exp Ophthalmol 1910;76:478-508.

8. Nagaki Y, Hayasaka S, Kitagawa K, Yamamoto S. Primary cornea guttata in Japanese patients with cataract: specular microscopic observations. Jpn J Ophthalmol 1996;40:520-5. 
9. Vail A, Gore SM, Bradley BA, Easty DL, Rogers CA. Corneal transplantation in the United Kingdom and the Republic of Ireland. Br J Ophthalmol 1993;77:650-6.

10. Brady SE, Rapuano CJ, Arentsen JJ, Cohen EJ, Laibson PR. Clinical indications for and procedures associated with penetrating keratoplasty 1983-1988. Am J Ophthalmol 1989;108:118-22.

11. Buxton JN, Preston RW, Riechers R, Guilbault N. Tonography in corneal guttata: a preliminary report. Arch Ophthalmol 1967;77:602-3.

12. Roberts CW, Steinert RF, Thomas JV, Boruchoff SA. Endothelial guttata and facility of aqueous outflow. Cornea 1984;3:5-9.

13. Pitts JF, Jay JL. The association of Fuchs' corneal endothelial dystrophy with axial hypermetropia, shallow anterior chamber and angle closure glaucoma. Br J Ophthalmol 1990;74:601-4.

14. Waring GO, Rodrigues MM, Laibson PR. Corneal dystrophies endothelial dystrophies. Surv Ophthalmol 1978;23:147-68.

15. Lipman RM, Rubenstein JB, Torczynski E. Keratoconus and Fuchs' corneal endothelial dystrophy in a patient and her family. Arch Ophthalmol 1990;108:993-4.

16. Miller CA, Krachmer JH. Endothelial dystrophies. In: Kaufman HE, Barron BA, et al., editors. The cornea. New York: Churchill Livingstone, 1988.

17. Waring GO, Font RL, Rodrigues MM, Mulberger RD. Alterations of Descemet's membrane in interstitial keratitis. Am J Ophthalmol 1976;81:773-85.

18. Krachmer JH, Schnitzer JI, Fratkin J. Corneal pseudoguttata: a clinical and histopathologic description of endothelial cell oedema. Arch Ophthalmol 1981;99:1377-81.

19. Olsen T. Is there an association between Fuchs' endothelial dystrophy and cardiovascular disease? Graefes Arch Clin Exp Ophthalmol 1984;221:239-40.
20. Mayer DJ. Clinical wide field specular microscopy. London: Baillière Tindall, 1984.

21. Yee RW, Matsuda M, Schultz RO, Edelhauser HF. Changes in the normal corneal endothelial cellular pattern as a function of age. Curr Eye Res 1985;4:671-8.

22. Bourne WM, Kaufman HE. Specular microscopy of human corneal endothelium in vivo. Am J Ophthalmol 1976;81:319-23.

23. Hoffer KJ, Kraff MC. Normal endothelial cell count range. Ophthalmology 1980;87:861-6.

24. Matsuda M, Yee RW, Edelhauser HF. Comparison of the corneal endothelium in an American and a Japanese population. Arch Ophthalmol 1985;103:68-70.

25. Krachmer JH, Purcell JJ, Young CW, Bucher KD. Corneal endothelial dystrophy: a study of 64 families. Arch Ophthalmol 1978;96:2036-9.

26. Bourne WM, Johnson DH, Campbell RJ. The ultrastructure of Descemet's membrane. III. Fuchs' dystrophy. Arch Ophthalmol 1982;100:1952-5.

27. Krachmer JH, Bucher KD, Purcell JS, Young CW. Inheritance of endothelial dystrophy of the cornea. Ophthalmologica Basel 1980;181:301-13.

28. Magovern M, Beauchamp GR, McTigue JW, Fine BS, Baumiller RG. Inheritance of Fuchs' combined dystrophy. Ophthalmology 1979;86:1897-920.

29. Cross HE, Maumenee AE, Cantolino SJ. Inheritance of Fuchs' endothelial dystrophy. Arch Ophthalmol 1971;85:268-72.

30. Kirkness CM. The corneal endothelial dystrophies. Ann Acad Med Singapore 1989;18:158-64.

31. Laing RA, Leibowitz HM, Oak SS, Chang R, Berrospi AR, Theodore JA. Endothelial mosaic in Fuchs' dystrophy: a quantitative evaluation with the specular microscope. Arch Ophthalmol 1981;99:80-3.

32. Olsen T. On the significance of a low endothelial cell density in Fuchs' endothelial dystrophy: a specular micrographic study. Acta Ophthalmol (Copenh) 1980;58:111-6. 